\title{
Assisting Ph.D. Completion Following a Natural Disaster
}

\author{
Lucy Johnston \\ University of Newcastle, Callaghan, Australia
}

lucy.johnston@newcastle.edu.au

\section{Thomas Wilson and Alexander Mackenzie University of Canterbury, Christchurch, New Zealand \\ thomas.wilson@canterbury.ac.nz; alexander.mackenzie@canterbury.ac.nz}

\begin{abstract}
This article describes the experiences and outcomes for 761 doctoral students enrolled at the University of Canterbury who had their research disrupted by a magnitude 6.2 earthquake on $22^{\text {nd }}$ February 2011. We describe the measures that were put in place to assist the students to continue their studies through continued disruption from aftershocks, dislocation, building demolition and remediation, equipment failure, and limited access to resources. We used data from a number of University databases and student surveys to assess the impact of the disruption on student outcomes, considering measures such as completion rates and times, attrition rates, and student satisfaction. Overall the findings showed little impact of the disruption on completion rates or student satisfaction and only a slight increase in completion times. We consider the impact of additional factors, such as temporary relocation, and draw attention to key lessons learned that may assist those confronted with similar situations in the future.
\end{abstract}

Keywords: doctoral studies, doctoral completion, attrition, disasters, supervision

\section{Introduction}

On 4 September 2010, a magnitude 7.1 earthquake approximately forty kilometers west of Christchurch, New Zealand's second largest city (population at the time 375,000), initiated a destructive sixteen month sequence of earthquakes (Quigley et al., 2012). Migrating east, this seismic activity was punctuated by four large earthquake events, the most destructive of which occurred on 22 February 2011. A fault ruptured directly under the city's southeastern suburbs

(CC BY-NC 4.0) This article is licensed to you under a Creative Commons Attribution-

NonCommercial 4.0 International License. When you copy and redistribute this paper in full or in part, you need to provide proper attribution to it to ensure that others can later locate this work (and to ensure that others do not accuse you of plagiarism). You may (and we encourage you to) adapt, remix, transform, and build upon the material for any non-commercial purposes. This license does not permit you to use this material for commercial purposes. resulting in a magnitude 6.2 earthquake that produced strong vertical ground acceleration in the central and eastern city suburbs, resulting in 185 deaths and over 6,500 injuries (Bannister \& Gledhill. 2012; Johnston et al., 2014). Tens of thousands of homes across the city were damaged and the city's central business district was immediately cordoned off, with over 1,100 buildings subsequently demolished. Widespread liquefaction throughout the eastern suburbs caused severe land and building damage, disrupting road networks and seriously 
compromising buried infrastructure networks (water, electricity and sewage) (Cubrinovski et al., 2011). Many households were without power, water, and sewage for periods of weeks or months. Ground damage due to liquefaction and slope stability hazards resulted in over 7,500 residential properties ( $\sim 5 \%$ of total housing stock) being deemed as either too expensive to remediate or too dangerous for residential occupation, requiring that residents relocate.

The 22 February 2011 Christchurch earthquake occurred on the second day of the first semester of the 2011 academic year. Located five kilometers from the city center in the north-western suburbs the campus was spared major immediate damage and no serious injuries or deaths occurred on the campus. The consequent impact of the earthquake on the university, its buildings, staff, and students was, however, severe. The university campus was completely closed to teaching and research staff and all students for three weeks whilst buildings were checked and plans put in place for a revamped teaching semester (Seville, Hawker, \& Lyttle. 2012). All the university buildings required thorough seismic inspection before they could be considered available for reoccupancy. A small number of large buildings have subsequently been, or are scheduled to be, demolished and all buildings have undergone, or are undergoing, extensive remediation and strengthening work, which requires temporary relocation by the occupants. When teaching restarted on campus it was in a group of large event marquees (tents). Two groups of 49 and 57 Portacoms (portable, temporary buildings) were subsequently erected, and these continue to serve as teaching spaces and staff and student offices, including temporary accommodation during periods of relocation, resulting in ongoing research disruption (Seville et al., 2012).

In this paper we consider the efforts that were made to assist doctoral students with continuing their studies and the outcomes for those students in terms of degree completion and student satisfaction. The efforts described occurred in a time of heightened stress for students, staff, and administrators - with disruption to living conditions, transport, workplace, schooling, and childcare (Potter, Becker, Johnston, \& Rossiter, 2015). Populations recently impacted by disasters report stress, anxiety, depression, and related health problems at rates higher than both similar pre-event populations and those in less impacted areas (Bonnano, Brewin, Kaniasty, \& La Greca, 2010; Dirkzwager, Kerssens, \& Yzermans, 2006; Ginexi, Weihs, Simmens, \& Hoyt, 2000). Continuing research and study under these circumstances is difficult, and here we reflect on what measures were implemented in our efforts to support the doctoral students and the consequences of these measures.

\section{Literature Review}

Few studies have considered the impact of disasters specifically on aspects of personal and academic functionality amongst tertiary students, and those that have are focused almost exclusively on the impact of hurricanes on US tertiary student populations (Gill et al., 2007, Van Willigen, Edwards, Lormand, \& Wilson, 2005). While some important differences do exist between earthquakes and hurricanes - most importantly the lack of warning for the former and the continued experience of aftershocks for months after the main event - the disruption and stress for those affected is similar.

Gill et al. (2007) considered the impact of Hurricane Katrina on two groups of tertiary students three months post-event - 3,410 students at Mississippi State University (MSU) and 7,100 students from three New Orleans universities. Although MSU students experienced significant disruption as a result of the Hurricane, few were forced to evacuate, and the main campus was only closed for two days (Gill et al. 2007). By contrast, the population of New Orleans was forced to evacuate, and most of the New Orleans university campuses were closed for the rest of the semester. Results showed both student populations to be suffering from elevated stress and anxiety levels in comparison to those unaffected by the hurricane event. However, the New Orleans students, those more directly affected, reported levels of depressive symptoms and loss of confidence three 
times higher than those reported by MSU students, which suggests a link between higher levels of direct disaster exposure and disruption and lower functionality. These findings are consistent with the much wider range of studies confirming a strong correlation between both the extent of exposure to disaster impact (including accommodation damage, and level of threat), and higher levels of stress, with poorer recovery outcomes (Bonnano et al. 2010; Norris et al. 2002). In this article we focus on the disruption to research experienced by the doctoral students but note that the range of disruption to homes and daily life varied considerably as a function of area of residence and personal situations.

Gill et al. (2007) also found that students from New Orleans universities were much less satisfied with the response operations of federal, local, and university authorities than were those enrolled at MSU. Prior research had indicated that the extent of perceived support is an important indicator of resilience and coping after disasters (Bonanno et al., 2010; Kaniasty \& Norris, 1993; La Greca, Silverman, Vernberg, \& Prinstein, 1996; Norris \& Kaniasty 1996). Perceived support - including the provision of accurate and timely information from authorities (Kaniasty \& Norris, 2009) - has been found to be predictive of lower stress levels and better adjustment and recovery outcomes (Norris \& Kaniasty 1996). Communication from authority sources, such as work or study places, is an important component in that provision of social support (e.g., Norris \& Kaniasty 1996). For example, when their university's communication systems failed completely in the days after Hurricane Ike, tertiary students reported feeling isolated and experienced comparatively high levels of post event stress and mental dysfunction seven months after that event (Watson, Loffredo, \& McKee, 2011). Conversely, tertiary students who perceived high levels of support provided by their university after Hurricane Floyd reported lower levels of stress and better recovery outcomes than did local residents of similar age and income bracket who did not have similar institutional support (Van Willigan et al., 2005). Accordingly, it is important that we reflect on the support offered to students and the impact of that support of students in order to learn lessons to enable the development of plans for any future natural disasters that disrupt tertiary studies.

In the next section we outline the various interventions that were put in place to assist doctoral students and detail the measurement tools that were accessed to enable an evaluation of student outcomes.

\section{Interventions}

The initial focus of the university was on provision of lectures for undergraduate students. The nature of doctoral research necessitated more detailed consideration of individual student research requirements and a mixture of general and specific, case-by-case provisions.

\section{Communication}

The University made immediate attempts, through a variety of media, to contact all students to ensure their safety and then to and provide them with information regarding the state of the University (Seville et al. 2012). Official University communications took many forms immediately post-quake, including notices in newspapers and radio announcements, email, University webpages, and social media. Subsequently the Dean of Postgraduate Research and supervisors made contact with each doctoral student to provide updates and to reassure the students regarding the university's efforts in regards to their continued study. The Dean continued to send email messages to all $\mathrm{Ph}$.D. students advising them of specific updates regarding university facilities and opportunities for Ph.D. students, such as relocations and extensions, as outlined below.

Facilitating doctoral students contact with the University, supervisors, peers, and family and friends was considered a high priority area to reduce students' sense of isolation and anxiety. Many students had left computers and other equipment and resources in their offices when the 
university was evacuated on 22 February 2011 and it took some time (days to weeks) before supervised access to recover such items became possible. To facilitate Ph.D. students' access to electronic media to receive communications and to be able to contact others - a particularly important consideration for international students who needed to contact relatives and friends overseas - the Postgraduate Office quickly purchased a number of laptop computers and mobile internet devices that were loaned to doctoral students who had lost internet access in their homes and/or had computers destroyed or rendered inaccessible within the university. One hundred and thirty-nine students received loans of mobile internet devices and fifty-nine received loans of a laptops. Use of the internet enabling devices was phased out as internet access was restored across the city and access to campus facilities with Wi-Fi capability was increased; use of the devices had stopped by June 2011. The laptops were returned when the students retrieved their own devices or got replacements.

With access to the vast majority of university buildings severely limited for an extended period of time, many doctoral students had difficulty finding appropriate space to study, especially those who suffered severe damage to homes and/or were without power and internet access for extended period of time. Similarly, there were limited places where students and supervisors could meet and discuss their research. Once a 'tent village' was erected for delivery of undergraduate lectures and tutorials (late March 2011), a small bookable tent was secured for doctoral students to meet with their supervisors. Subsequently (in late April) three Portacoms on the edge of campus were secured as a "postgraduate village". This consisted of two study rooms, each equipped with Wi-Fi capability and one containing 10 PCs and a networked printer, and a social space with some kitchen facilities. The village was accessible through swipe-card access to thesis students twentyfour hours a day seven days a week. This facility was heavily used by students, not only as a study space but also as a place to meet peers and provide one another with social and practical support.

\section{Extensions to Thesis Submission Deadlines}

Doctoral students must submit their thesis for examination within 4 full-time equivalent years. Accordingly, any time lost during candidature increases stress for students trying to meet this deadline. All students enrolled at the time of the February 2011 earthquake were granted a twomonth extension to their thesis submission date, in recognition of the period of closure of the university and the less than ideal subsequent study environment (including no physical access to the university libraries, only the electronic collections for a number of months). No tuition fees were charged to students for this extension period; the fees were covered by the University's business continuity insurance cover. For students in receipt of a UC-funded scholarship the monthly stipend was also extended, covered by the insurance policy. Some, but not all, external scholarship funders also extended the period of fees and scholarships payments after petition from the university.

In addition to this automatic extension, doctoral students could also submit applications for additional periods of extension if the disruption caused to their research was greater than that which could be covered by a two-month extension period - for example, when experiments had to be restarted, where essential equipment was out of commission, or where access to field sites or populations was restricted. Some students had to wait months for plant samples to be regrown, for new fish to be sourced to replace those that had died, for technicians to arrive from overseas to recalibrate microscopes, and to find new sample populations after childcare centres with which they were worked closed permanently. Applications for additional periods of extension required details of the disruption caused to the students' research, with support from the supervisory team. (The insurance policy would not cover disruption to study caused by external events (e.g., house damage).) 


\section{Temporary Relocations}

In order to facilitate the continuity of research, especially when it required access to resources of equipment that would not be available for some time, students were offered the opportunity to undertake a temporary relocation. Forty-six Ph.D. students, made up of two distinct cohorts, took up this opportunity.

One cohort of twelve students spent the Trinity Term (May/June 2011) at the University of Oxford at the invitation of the Vice-Chancellor and the Colleges of the University of Oxford. (Two of the doctoral students were invited by their supervisors at Oxford to extend their stay.) The disciplines in which supervision and research space was available for doctoral students was provided by Oxford and senior (second and third year) Ph.D. students were invited to apply for consideration. Successful applicants were selected by the Dean of Postgraduate Research based on matching of research areas of student and available supervision and on references from UC supervisors. Students were hosted at no cost by one of the University of Oxford Colleges or Permanent Private Halls and the University of Canterbury covered the student airfares from Christchurch to Oxford.

Thirty-four other Ph.D. students undertook ad-hoc relocations, seventeen within New Zealand and seventeen overseas (in Australia, Canada, France, Norway and the USA), primarily in institutions where supervisors had existing research collaborations or personal connections. The majority of these students (76\%) were from the Colleges of Science and Engineering and relocation allowed the students access to laboratory facilities and equipment there were rendered unavailable or inoperable at Canterbury. The mean time away from UC was 53 days with a range between 3 and 159 days. Half of the relocations occurred within 2 months of the earthquake and all bar two had commenced within 5 months of the February earthquake. Applications for temporary relocations were made to the Dean of Postgraduate Research who approved those where she was confident that the following conditions were met: (i) the facilities being made available to the student were appropriate for their research; (ii) relocation would enable the student to return to study promptly and enable completion of the research more quickly than if the student were to remain at Canterbury and wait for their facilities to become available; (iii) an appropriate plan for supervision had been set in place - that the nature (e.g., Skype, email) and frequency of supervision meetings had been determined; (iv) an academic mentor/supervisor was available in the host institution to offer day-to-day guidance to the student; (v) the relocation had the support of the supervisors and Head of Department/School. The university covered any new direct research costs associated with the relocation (e.g., purchase of consumables, equipment charges), student airfares to their relocation venue and a weekly stipend (the amount of which varied according to location). Students who undertook a relocation were not eligible for additional extensions to their thesis submission date based on lack of access to University of Canterbury facilities.

\section{Method}

In order to evaluate the performance of those doctoral candidates who were enrolled at the time of the 2011 earthquake, we accessed a variety of quantitative data sources, as detailed below. These data are a combination of student candidature data (e.g., commencement and submission dates) and student satisfaction surveys. With the exception of the post-earthquake survey described below all the measures are ones that are regularly collected and, accordingly, allow for comparisons between those candidates enrolled at the time of the earthquake and other doctoral candidate cohorts.

\section{Measures}

Data from a number of University-based surveys and databases were obtained in order to assess student outcomes and satisfaction. 


\section{Post-Earthquake Survey}

Three months after the February earthquake a campus-wide survey of all students was conducted by the Institutional Research Team (see Beaven et al., 2014, for further details of the survey materials). For this paper we extracted data from Ph.D. student respondents regarding University communication post-quake. Specifically we looked at the responses to two questions: "When were you able to access University updates post-quake?" (response options: that evening; the day after; within a week; within two weeks; other) and "How helpful did you find the University updates?" (response options: not useful; useful; very useful).

\section{Doctoral Student Databases}

The Postgraduate Office maintains databases of student outcomes for all doctoral candidates. From these databases the following data were extracted for all of the doctoral students enrolled at the University at the time of the earthquake in March 2011 and for comparison cohorts of all doctoral students who commenced their studies in 2006, 2007, 2008, 2009, and 2010.

\section{Student outcomes.}

Each student was categorized as having been awarded a Ph.D.; undergoing thesis examination; still enrolled in Ph.D. studies; withdrawn or lapsed from their studies; or other (e.g., transferred to a masters degree). Three key percentages were then calculated from these data: (i) the percentage of each cohort who had successfully completed a Ph.D.; (ii) the maximum possible percentage completions (total of those awarded, those under examination and those still enrolled); (iii) the percentage of each cohort who had withdrawn from their studies or had their studies terminated due to lack of progress.

\section{Completion times.}

For each completing student the time between initial enrolment in a Ph.D. and submission of the Ph.D. for examination was calculated. In computing completion times any periods of suspension of study were omitted and any periods of part-time enrolment were pro-rated for full-time equivalence. (At the University of Canterbury part-time Ph.D. enrolment is given a weighting of .65 of a full-time load.) For those students enrolled during the February 2011 earthquake, two completion times were calculated: (i) time between enrolment and submission; (ii) time between enrolment and submission with the exclusion of any earthquake-based extensions granted. Further, the percentage of students in each cohort who completed within the equivalent of four full-time years of study, which is the maximum time for which government funding for doctoral students is received, was computed.

\section{Student Satisfaction}

The University conducts a number of student surveys assessing student satisfaction. For this paper, data was extracted from two of the surveys of Ph.D. students: The University of Canterbury Postgraduate Experience Questionnaire (UCPEQ; for development of this survey see Sampson, Johnston, Comer, \& Brogt, 2016) and the University of Canterbury Postgraduate Student Exit Survey introduced.

\section{University of Canterbury Postgraduate Experience Questionnaire (UCPEQ).}

This comprehensive survey, introduced in 2004, is distributed to Ph.D. students every two-years. It is a cross-sectional survey of all Ph.D. students enrolled on a selected data and addresses issues related to the supervisory relationship, the provision of resources, and the academic environment. For this paper we considered only the overall measure of satisfaction with their Ph.D. experience (not at all satisfied; somewhat satisfied; unsure; satisfied; very satisfied). 


\section{Exit Survey.}

Once the examination process is completed all Ph.D. students are invited to complete a brief online survey, introduced in 2012, asking about satisfaction with the examination process and with the Ph.D. experience as a whole. For this paper we considered only the overall measure of satisfaction with their Ph.D. experience (not at all satisfied; somewhat satisfied; unsure; satisfied; very satisfied).

\section{New enrolments.}

The number of commencing Ph.D. students each year from 2006 to 2014 was obtained from the Postgraduate Office student database.

\section{Results}

The results are presented in two sections. Student outcomes are reported first, presenting the completion and attrition rates for candidates in the earthquake cohort in comparison to those from previous years and also the time to completion for these cohorts. Levels of student satisfaction are then reported, again comparing those enrolled at the time of the 2011 earthquake and those from prior cohorts.

\section{Student Outcomes}

Outcomes for the 761 students enrolled at the time of the 22 February 2011 earthquake are shown in Figure 1, along with corresponding outcomes for the cohorts of Ph.D. students who commenced Ph.D. study in each of 2006, 2007, 2008, 2009, 2010. (It is acknowledged that there is some overlap in the later cohorts (2008 onwards) and the EQ cohort.)

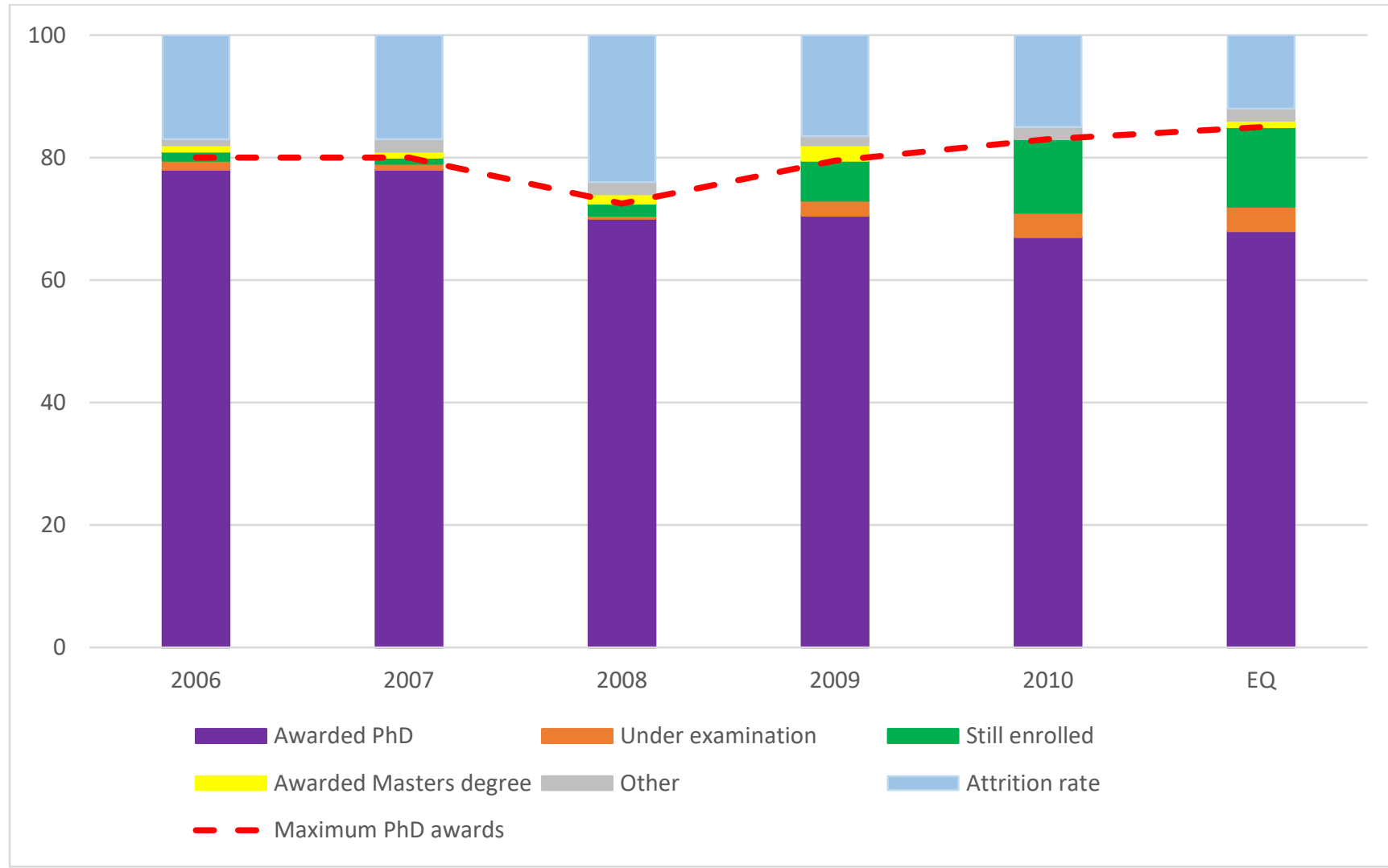

Figure 1: Student Outcomes as a function of cohort 
The percentage of students enrolled at the time of the February 2011 earthquake who completed their Ph.D. and the maximum possible completion percentage is comparable to, and even somewhat higher than, prior enrollment years. Similarly, the attrition rate (withdrawals) is somewhat lower.

Student outcomes are further compared in Figure 2 for those students who remained at the University of Canterbury and those who temporarily relocated to another institution, either to the University of Oxford or on ad-hoc relocations. As can be seen, there were some differences in these cohorts. Most notably the attrition rates were somewhat higher amongst those students who relocated, although it is noted that the absolute numbers are low.

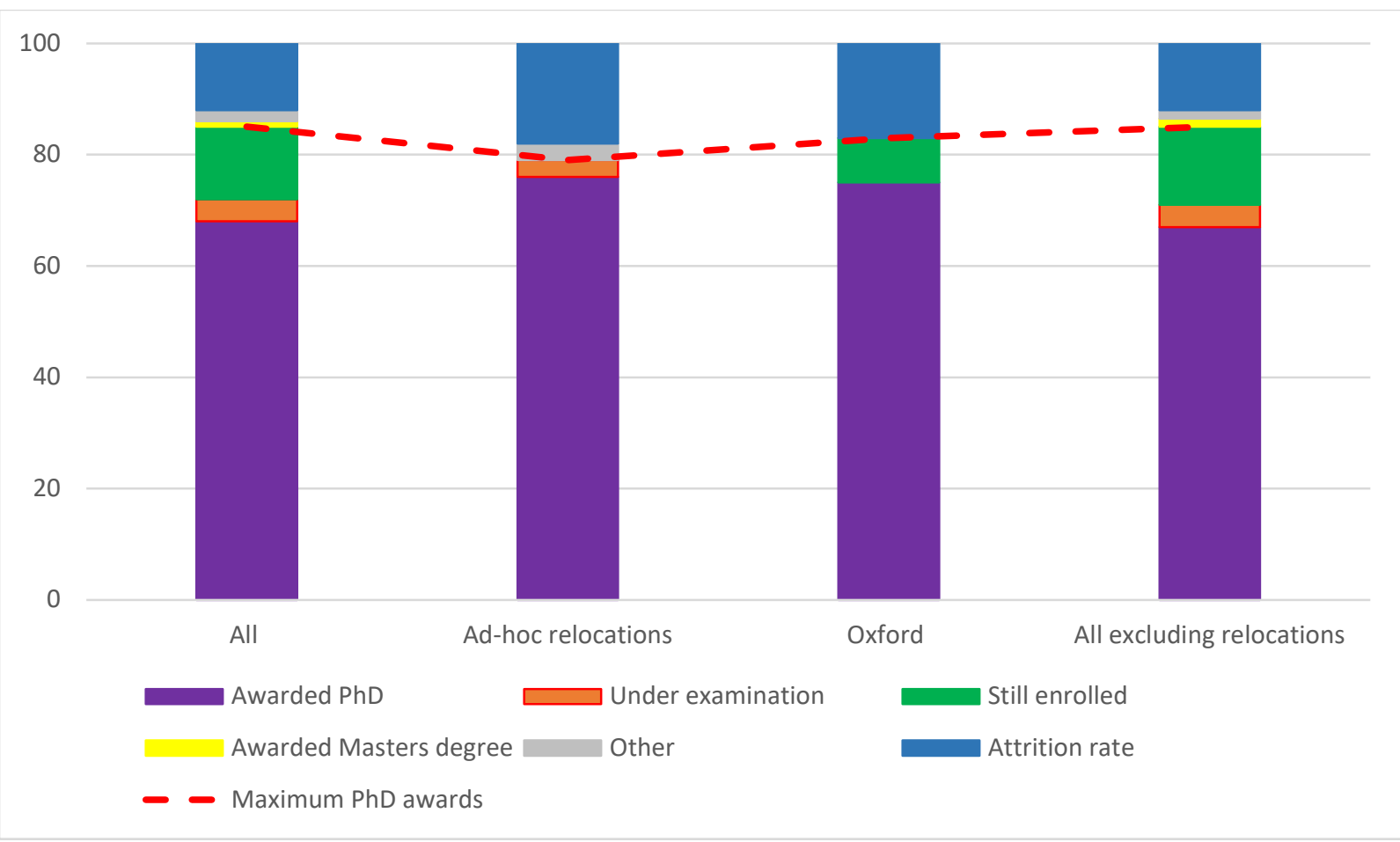

Figure 2: Student Outcomes as a function of relocation

\section{Attrition rates}

Further details of the attrition rates are shown in Figures 3 and 4. The attrition rates for doctoral cohorts from 2006 have varied between $15 \%$ and $24 \%$ (It is acknowledged that these could rise slightly if the students currently enrolled from these cohorts do not complete their degrees) while the attrition rate from the EQ cohort is only $12 \%$. Even were a substantial proportion of those students still enrolled not to complete their degree, the attrition rates would be similar to, or lower than, those of other cohorts. 


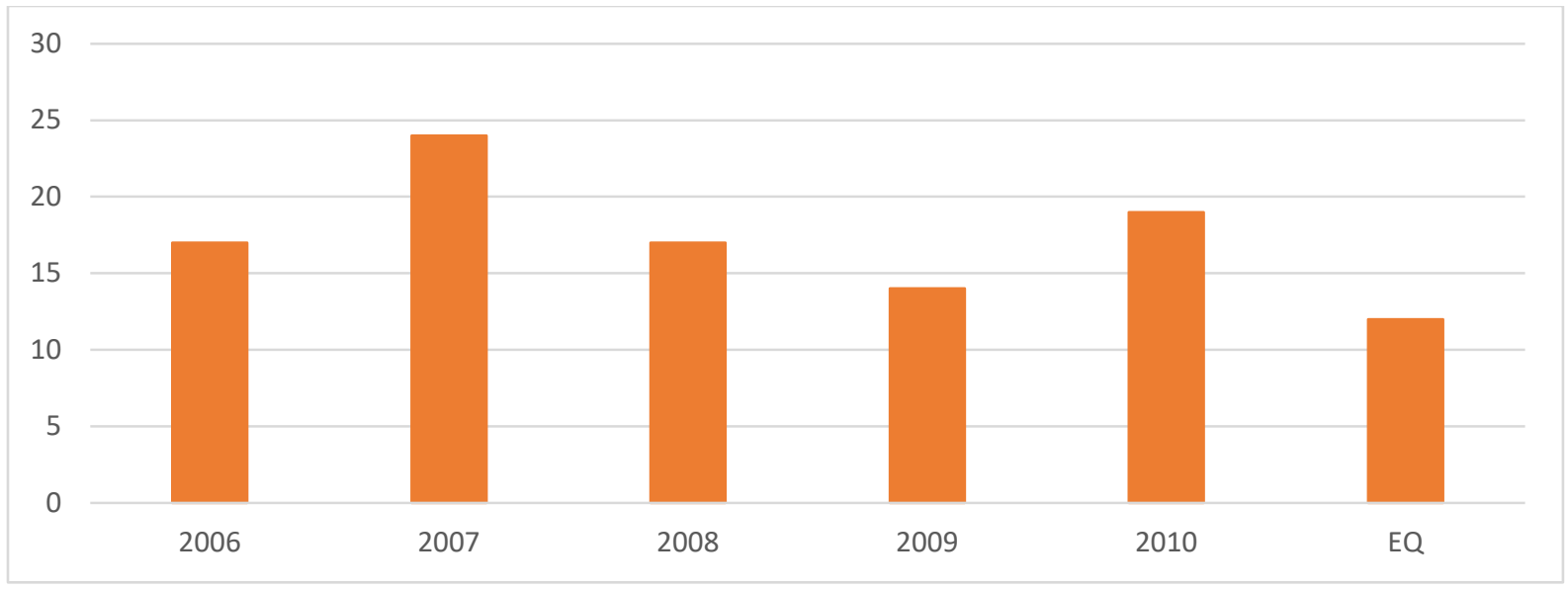

Figure 3: Percentage of doctoral students withdrawing from their studies as a function of cohort

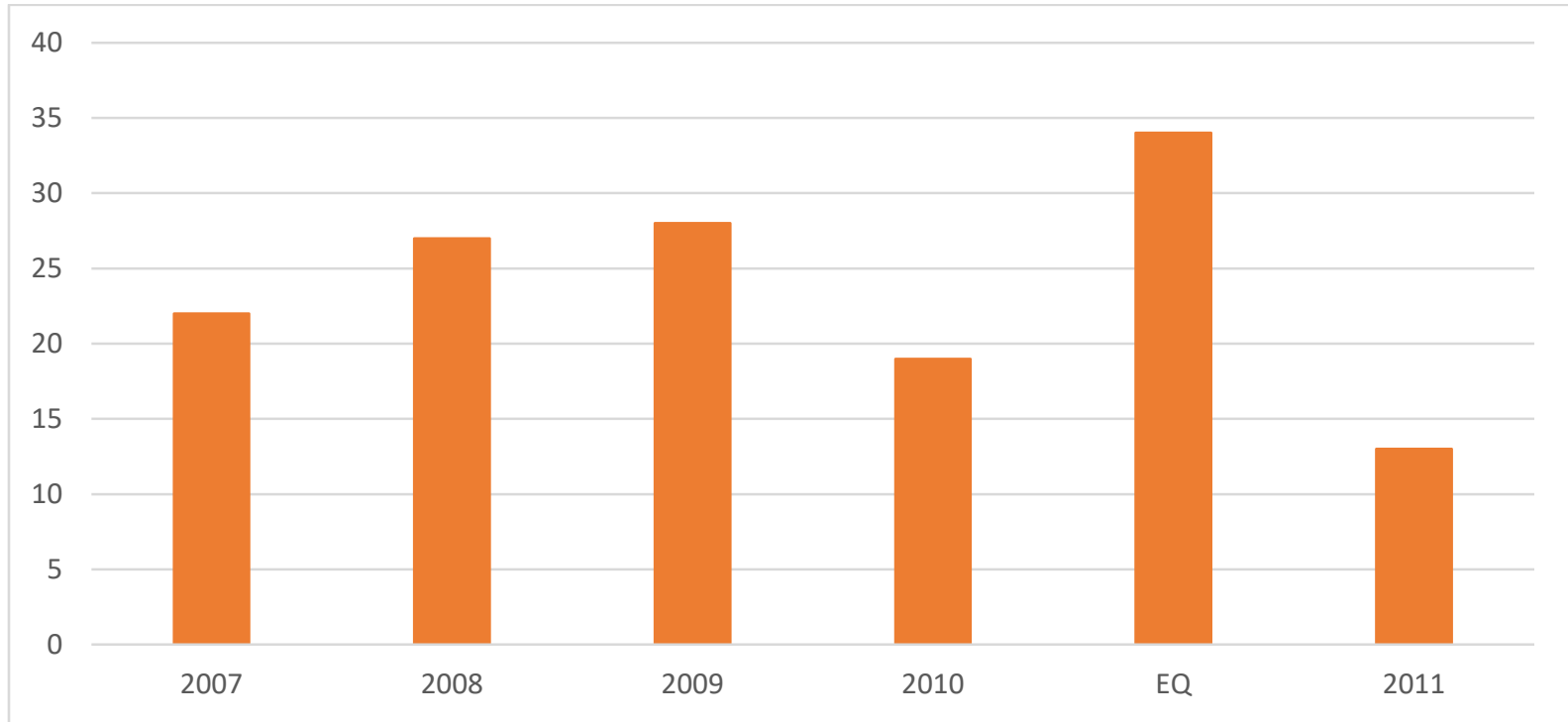

Figure 4: Mean time (months) to withdrawal from Ph.D. studies as a function of cohort

Only $6(<1 \%)$ doctoral students withdrew in the three months following the February 2011 earthquake, in contrast to approximately $20 \%$ of undergraduate students who withdrew during this period. Two of the doctoral students who withdrew were domestic and four were international students, proportions that match the overall distribution of domestic and international Ph.D. students. Three students who commenced their Ph.D. in these three months also subsequently withdrew from their studies, after a mean enrolment period of nine months. For the whole of 2011 there were $23(3 \%)$ doctoral student withdrawals. To date, $14 \%$ of students who first enrolled in a Ph.D. in 2011 have withdrawn from their studies, a rate comparable with other years.

\section{Submission Times}

Table 1 shows submission times. Mean time to submission was close to the maximum funding limit of 4 full-time equivalent years (4 EFTS) for each cohort and was substantially higher than prior cohorts. Mean time to submission was somewhat longer for those who undertook a temporary relocation than for those who remained in Christchurch (4.23 vs. 3.98 EFTS). (Mean completion time will increase slightly for the overall cohort as those still enrolled complete their degrees) 
The mean time for all cohorts was below 4 EFTS once the EQ-based extension periods had been subtracted, however, though still somewhat longer for those who had relocated. Approximately half of the students completed the Ph.D. within 4 EFTS, though the percentage was notably smaller for the Oxford cohort.

Two hundred and thirty-one doctoral students (30\% of those enrolled) received an additional period of extension, ranging from 1 to 12 months $(\mathrm{M}=3.3$ months $)$. As with the automatic twomonth extension, students were charged no fees for the period of extension. Such applications could be submitted up until two years after the earthquake $\left(21^{\text {st }}\right.$ February 2013$)$, recognizing that the impacts could not always be anticipated in the immediate aftermath of the earthquake. Excluding the EQ-based extension periods, the proportion submitting within the research degree completion time rose to nearly two-thirds.

Table 1: Time to submission for Ph.D. students as a function of cohort

\begin{tabular}{|l|c|c|c|c|}
\hline Cohort & $\begin{array}{l}\text { Mean time to } \\
\text { submission* }\end{array}$ & $\begin{array}{l}\text { Mean time to } \\
\text { submission ex- } \\
\text { cluding EQ-based } \\
\text { extensions }\end{array}$ & $\begin{array}{l}\text { \% completing } \\
\text { within specified } \\
\text { RDC (4 EFTS) }\end{array}$ & $\begin{array}{l}\text { \% completing } \\
\text { within specified } \\
\text { RDC (4 EFTS), } \\
\text { excluding EQ- } \\
\text { based extensions }\end{array}$ \\
\hline $\begin{array}{l}\text { All students enrolled at } \\
\text { time of February 2011 } \\
\text { earthquake (N=761) }\end{array}$ & 3.99 EFTS & 3.70 EFTS & $52 \%$ & $64 \%$ \\
\hline $\begin{array}{l}\text { Students who undertook } \\
\text { ad-hoc relocations } \\
\text { (N=34) }\end{array}$ & 4.24 EFTS & 3.92 EFTS & $43 \%$ & $65 \%$ \\
\hline $\begin{array}{l}\text { Students who undertook } \\
\text { a relocation to the Uni- } \\
\text { versity of Oxford } \\
\text { (N=12) }\end{array}$ & 4.23 EFTS & 3.93 EFTS & $22 \%$ & $67 \%$ \\
\hline $\begin{array}{l}\text { All excluding reloca- } \\
\text { tions (N=715) }\end{array}$ & 3.98 EFTS & 3.69 EFTS & $53 \%$ & $65 \%$ \\
\hline $\begin{array}{l}\text { Submissions in 12 } \\
\text { months prior to Febru- } \\
\text { ary earthquake (N=124) }\end{array}$ & 3.54 EFTS & 3.54 EFTS & $73 \%$ & $73 \%$ \\
\hline
\end{tabular}

* part-time enrolment is pro-rated at .65 EFTS

\section{Student Satisfaction}

\section{University Communication.}

Three hundred and sixty-six Ph.D. students (48\% of those enrolled at the time of the earthquake) responded to the Institutional survey. As shown in Figure 5, they were able to access information from the University quickly and found the information provided to be useful. Over half of the students who responded (57\%) indicated that they had been able to access University updates within a day of the earthquake and nearly all (93\%) within a week. Nearly all of those who responded $(90 \%)$ evaluated the university updates as being useful or very useful. 

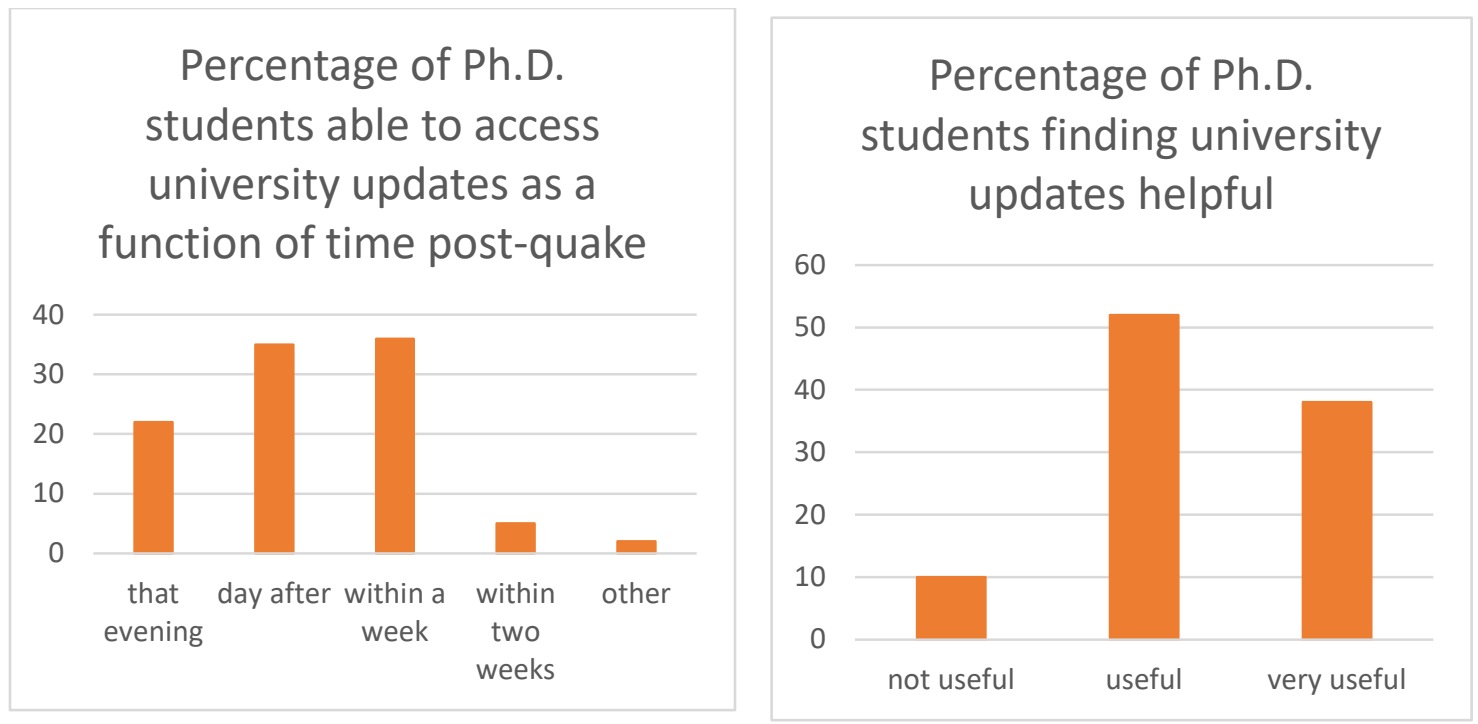

Figure 5: Ph.D. student access to university information (left-hand panel) and perceived usefulness of that information (right-hand panel)

\section{UCPEQ}

The UCPEQ was completed in 2010 (prior to the September 2010 earthquake), 2012, and 2014 and the Exit Survey has been available since 2012 with results collated annually. Figure 6 shows the percentage of students who indicated being satisfied or highly satisfied with their student experience on each of the surveys. As can be seen, overall satisfaction levels are high, at approximately $80 \%$ satisfaction, and there was only minimal decline in this level in the post-2011 earthquake surveys compared to the pre-earthquake survey of 2010.

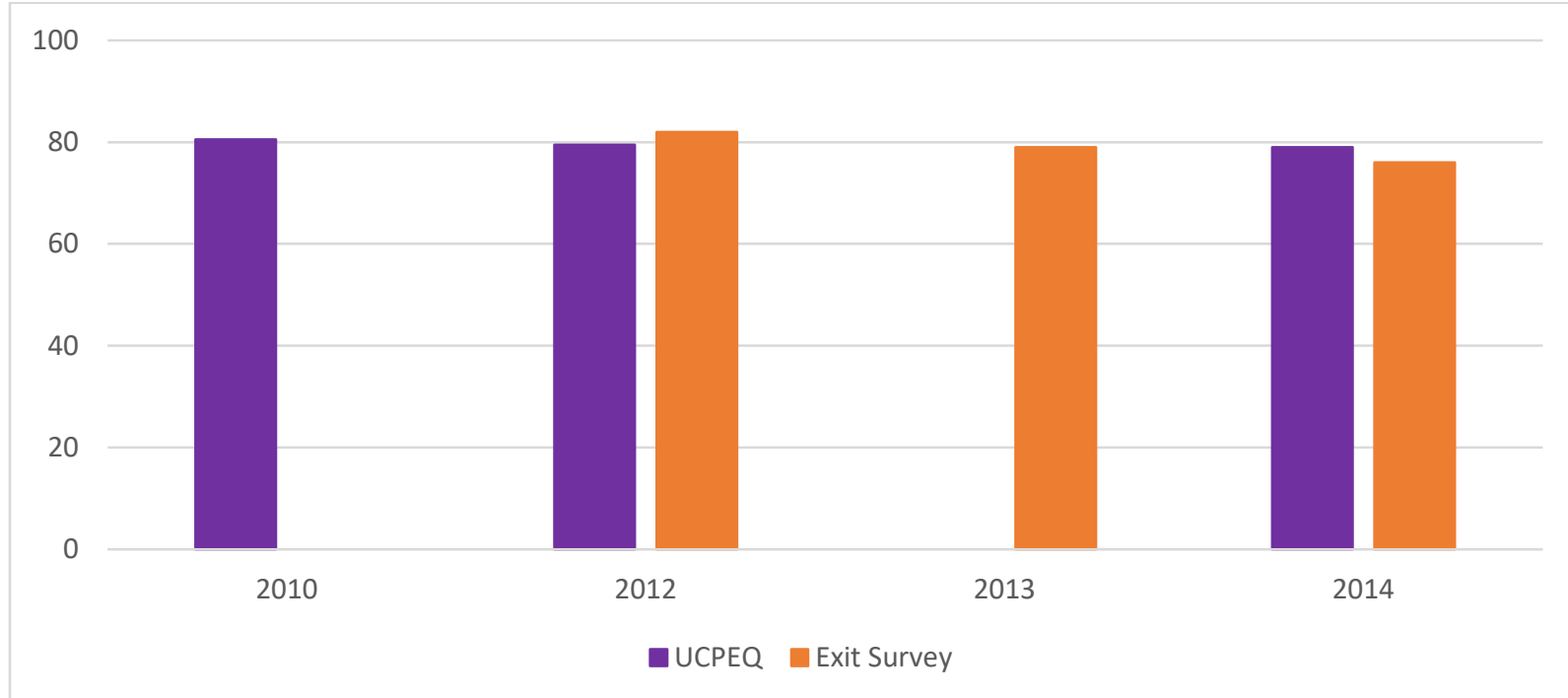

Figure 6: Percentage of doctoral students satisfied or highly satisfied with their doctoral experience

\section{New Enrolments.}

As shown in Figure 7, the number of new doctoral enrolments did suffer a slight decline in 2011 but has since returned to pre-earthquake levels. (Doctoral students can commence their studies on the first of any month throughout the year.) 


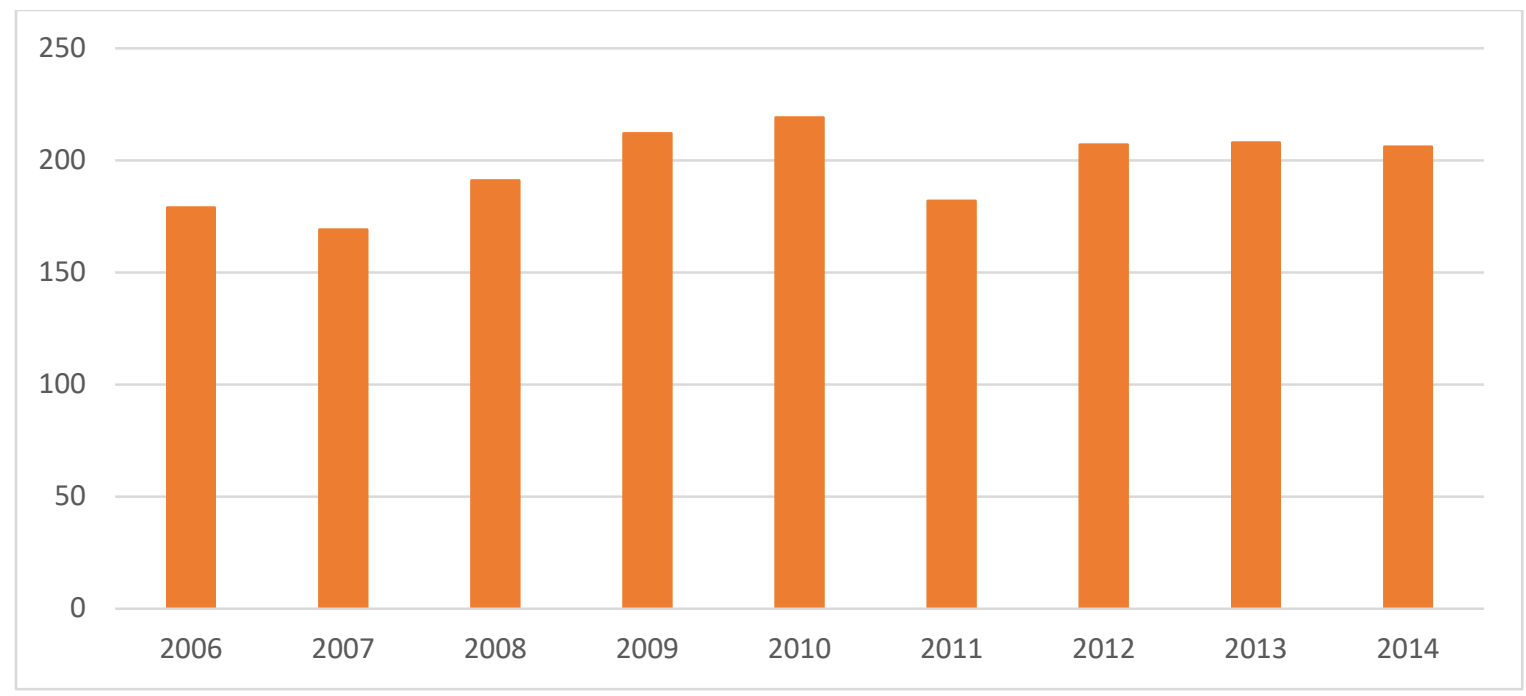

Figure 7: New doctoral enrolments as a function of year

\section{Discussion}

In this paper we have documented the interventions put in place to assist $\mathrm{Ph} . \mathrm{D}$. students who were enrolled at the time of the February 2011 Christchurch earthquake and the outcomes for these students. In this section we reflect on those interventions in light of the student outcomes. In doing so, we highlight lessons that can be learned that might assist others not only in dealing with the aftermath of natural disaster but also planning for the occurrence of such and hence mitigating the disruption caused. Also, a number of learning legacies are described - things introduced in response to the post-earthquake situation that have been subsequently retained.

Prior research has highlighted the importance of clear and timely communication from authority sources, including work or study places on individual wellbeing post-disaster (Kaniasty \& Norris, 2009; Norris \& Kaniasty, 1996). The University quickly made contact with students and continued to provide frequent and detailed updates via multiple media outlets. The $\mathrm{Ph}$.D. students who responded to the subsequent institutional survey students indicated that they were quickly able to access that information and found it useful. This communication likely led to perceptions of strong institutional support and facilitated better recovery outcomes (Van Willigan et al., 2005). The perception of institutional support is also seen in the high student satisfaction ratings, both during and at the completion of candidature. Our findings, then, reinforce the previous research documenting the importance of communication with, and support for, students after natural disaster. The Dean supplemented the general University information with information specific to research students. One of the learning legacies is a bi-weekly email memo to research students and a monthly memo to departmental postgraduate coordinators and heads of department from the Dean; the need for rapid and targeted communications post-quake highlighted the need for timely communication of pertinent information to this group. Additional legacies are the retention (and replacement and upgrading) of a number of the purchased laptops that are made available to doctoral students for short-term use during their candidature (e.g., to enable mobile data collection) and the retention of a research student space on campus. This space contains both study rooms, social space, and a free peer research advice service to continue to enhance the doctoral research culture.

Despite significant disruption to life and study, the outcomes for those Ph.D. students enrolled during the 2011 earthquake were remarkably similar to those of comparison cohorts. A similar proportion of students was successful in achieving their doctoral degrees as for previous cohorts 
and the attrition rate from these students was actually somewhat lower than for other cohorts. Despite the adversity of the earthquakes, Ph.D. students remained committed to completing their studies. Not only was the attrition rate for these students somewhat lower than for comparable doctoral cohorts, it contrasts sharply with the high attrition seen amongst undergraduate students ( $20 \%)$, especially among commencing undergraduate students. The Ph.D. students who did withdraw from their studies in the earthquake aftermath were not, as might be expected, new doctoral students who could have relatively easily left and commenced study elsewhere. Instead, the students who withdrew had been enrolled on average nearly three years, a longer mean time to attrition than for previous cohorts. For this group, the earthquake disruption may have been the final straw on a difficult journey. Such a long mean time prior to withdrawal is, of course, a concern given the time, effort, and finances invested by student, supervisors, the university, and the government to that point without a successful outcome. This finding offers insight for future disaster situations in terms of identification of a vulnerable population. Attention and support needs to be given to those students toward the end of candidature, especially if they have been progressing slowly or encountered difficulties in their study. It is important, of course, to support new students who are in an unfamiliar situation but equally it is important to minimize loss of established students.

The mean time to submission was somewhat higher than for prior cohorts, and the percentage submitting within the four full-time year equivalent (EFTS) period somewhat lower. However, once the earthquake-based extensions were removed, the mean completion time was similar to other cohorts and a high percentage completed within 4 EFTS. Provision of periods of extension with zero fees were intended to reduce the immediate concerns of both students and supervisors regarding time to submission and to allow necessary time for the appropriate completion of the student's research. Students not in receipt of a scholarship at the time of the earthquake $(\sim 40 \%)$ did have to cover their living costs for the period of extension and hence they incurred financial costs associated with an unexpected and unavoidable increase in their candidature.

The University insurers would not cover living expenses costs. The approval of insurance funding for the additional extensions (beyond the automatic two-month) were limited to situations where the extension was required specifically due to disruption to research-related activities or facilities. Any extensions requested to submission dates as a result of personal disruption (house, family, schools) of either student or supervisor were not covered by the insurance policy. Accordingly, such extension requests were very closely scrutinized and only those that could be covered by the business-interruption insurance policy were granted as earthquake-based extensions. While there was severe disruption to university facilities necessitating extensions, many students were more severely impacted by personal circumstances such as loss of their homes. These students had to absorb the impact of these factors on their studies through application for extensions or through suspension of study, which could also negatively impact research momentum and delay the date of completion of the degree. How to mitigate financial stress associated with extended study periods which are an inevitable consequence of natural disasters that result in campus closures or disruptions remains a major issue in planning for dealing with disasters. The financial burden is especially great for those students not in receipt of a scholarship as they have no insurance protection. Consideration might be given to the development of a contingency fund for research students to access during times of disaster.

The outcomes for those students who undertook temporary relocations are interesting. This group had longer submission times and higher attrition rates than did those students who did not relocate. Aimed at allowing students to resume research more quickly, these relocations may also create additional challenges for the relocating students. The longer submission time is, perhaps, not surprising. While these students did not have the daily turmoil of the post-earthquake environment to contend with and could access research facilities easily, they did have to adapt to a 
new working environment and supervisors. In addition, they had to readapt to the changed environment when they returned at the end of their period of relocation. Findings from the September 2010 earthquake showed those students who temporally left the city after the earthquake took longer to feel safe once they returned to the city, reported taking longer to feel okay, and perceived the effects of the earthquake on their study as being greater than those who remained (Beaven et al., 2014). Relocations might, then, have facilitated a return to research, and hence provided immediate benefit to students, but did not fully negate the impacts of the earthquake on these students. While leaving the city provided the students with the ability to resume their studies, it is possible that being away from city at the same time made it harder for these students to adjust to the earthquake aftermath such that this adjustment only occurred once they returned to the city weeks or months later. Those who left the city also left established social networks and may have accordingly suffered from less perceived social support than did those who remained. Such difficulties with returning from relocation is consistent with the finding of higher attrition amongst those who left Christchurch. (No student attrited from their students during a period of relocation. All such attritions occurred after return from the temporary relocation.) A lesson learned, therefore, is that attention needs to be paid to supporting relocating students on their return to campus. Again this points to the identification of a potentially vulnerable group and the need for close support for these students when they return from their temporary relocation.

While the focus of this manuscript has been on the experience and performance of the doctoral students enrolled at the time of the 2011 earthquake, new doctoral enrolments can also provide a marker of performance of the UC doctoral programme as a whole. The maintenance of the commencing doctoral enrolments numbers following the 2011 earthquake suggests that the reputation of the University as a provider of research degrees was not adversely disrupted by the disaster.

Overall the Ph.D. students enrolled at the time of the February 2011 earthquake performed well, with outcomes broadly similar to those of other doctoral cohorts. A student population who suffered disruption as a consequence of a natural disaster showed some negative impact on their studies, as seen in previous such cohorts (e.g., Gill et al., 2007). Consistent with previous research, provision of institutional support and communication was linked to student recovery and performance (e.g., Bonnano et al., 2010; Kaniasty \& Norris, 2009). Our review has enabled us to identify, in hindsight, some particularly vulnerable groups of student. Future planning for disaster impact and mitigation should have such groups identified and specific support in place for these students. In addition we identified a number of learning legacies around communication and support for Ph.D. candidates.

\section{References}

Bannister, S., \& Gledhill, K. (2012). Evolution of the 2010-2012 Canterbury earthquake sequence. New Zealand Journal of Geology and Geophysics, 55, 295-304. DOI:10.1080/00288306.2012.680475

Beaven, S., Wilson, T. M., Johnston, L., Brogt, E., Blyth, J., Reugg, C., . . Lyttle, J. (2014). Risk and resilience factors reported by a New Zealand tertiary student population after the $4^{\text {th }}$ September 2010 Darfield earthquake. University of Canterbury Internal Report.

Bonnano, G. A., Brewin, C. R., Kaniasty, K., \& La Greca, A. M. (2010). Weighing the costs of disaster: consequences, risks and resilience in individuals, families and communities. Psychological Science in the Public Interest, 11(1), 1-49. DOI: 10.1177/1529100610387086

Cubrinovski, M., Bradley, B., Wotherspoon, L., Green, R., Bray, J., Wood, C., \& Wells, D. (2011). Geotechnical aspects of the 22 February 2011 Christchurch earthquake. Bulletin of the New Zealand Society of Earthquake Engineering, 44(4), 205-226.

Dirkzwager, A. J. E., Kerssens, J. J., \& Yzermans, C. J. (2006). Health problems in children and adolescents before and after a man-made disaster. Journal of the American Academy of Child and Adolescent Psychiatry, 45(1), 94-103. DOI:10.1097/01.chi.0000186402.05465.f7 
Gill, D. A., Clarke, L., Cohen, M. J., Ritchie, L. A., Ladd, A. E., Meinhold, S., \& Marshall, B. K. (2007). Post-Katrina guiding principles of disaster social science research. Sociological Spectrum, 27, 789792. DOI: $10.1080 / 02732170701534283$

Ginexi, E. M., Weihs, K., Simmens, S. J., \& Hoyt, D. R. (2000). Natural disaster and depression: A prospective investigation of reactions to the 1993 midwest floods. American Journal of Community Psychology, 28(4), 495-518. DOI: 10.1023/a:1005188515149

Johnston, D. M., Standring, S., Ronan, K., Lindell, M., Wilson, T. M., Cousins, J., . . Bissell. R. (2014). The 2010/2011 Canterbury earthquakes: Context and cause of injury. Natural Hazards 73(2), 627-637. DOI: $10.1007 / \mathrm{s} 11069-014-1094-7$

Kaniasty, K., \& Norris, F. H. (1993). A test of the social support deterioration model in the context of natural disaster. Journal of Personality and Social Psychology, 64(3), 395.

Kaniasty, K., \& Norris, F. H. (2009). Distinctions that matter: Received social support, perceived social support, and social embeddedness after disasters. In Y. Neria, S. Galea, \& F. Norris (Eds.), Mental health and disasters (pp. 175-202). Cambridge, UK \& New York: Cambridge University Press. DOI: 10.1017/cho9780511730030.011

La Greca, A. M., Silverman, W. K., Vernberg, E. M., \& Prinstein, M. J. (1996). Symptoms of posttraumatic stress in children after Hurricane Andrew: a prospective study. Journal of consulting and clinical psychology, 64(4), 712.

Norris, F. H., \& Kaniasty, K. (1996). Received and perceived social support in times of stress: A test of the social support deterioration deterrence model. Journal of Personality and Social psychology, 71(3), 498. DOI: $10.1037 / 0022-3514.71 .3 .498$

Norris, F. H., Friedman, M. J., Watson, P. J., Byrne, C. M., Diaz, E., \& Kaniasty, K. (2002). 60,000 disaster victims speak: Part I. An empirical review of the empirical literature, 1981-2001. Psychiatry, 65(3), 207-239.

Potter, S. H., Becker, J. S., Johnston, D. M., \& Rossiter, K. P. (2015). An overview of the impacts of the 2010-2011 Canterbury earthquakes. International Journal of Disaster Risk Reduction, 14(1), 6-14. DOI: 19.1016/j.ijdrr.2015.01.014

Quigley, M., Van Dissen, R., Litchfield, N., Villamor, P., Duffy, B., Barrell, D., . . Noble, D. (2012). Surface rupture during the $2010 \mathrm{Mw} 7.1$ Darfield (Canterbury, New Zealand) earthquake: Implications for fault rupture dynamics and seismic-hazard analysis, Geology 40(3), 1-4. DOI: 10.1130/g32528.1

Sampson, K., Johnston, L., Comer, K., \& Brogt, E. (2016). Developing evidence for action on the postgraduate experience: An effective local instrument to move beyond benchmarking. Higher Education Research and Development, 3(2), 337-341. DOI: 10.1080/07294360.2015.1087469

Seville, E., Hawker, C., \& Lyttle, J. (2012). Resilience tested: A year and a half of ten thousand aftershocks. University of Canterbury. Available from: http://www.canterbury.ac.nz/emergency/documents/resiliencetested.pdf

Watson, P. G., Loffredo, V. J., \& McKee, J. C. (2011). When a natural disaster occurs: Lessons learned in meeting students' needs. Journal of Professional Nursing, 27(6,) 362-369. DIO: 10.1016/j.profnurs.2011.09.001

Van Willigen, M., Edwards, B., Lormand, S., \& Wilson, K. (2005). Comparative assessment of impacts and recovery from hurricane floyd among student and community households. Natural Hazards Review, 6(4), 180-190. DOI: 10.1061/1527-6988 


\section{Biographies}

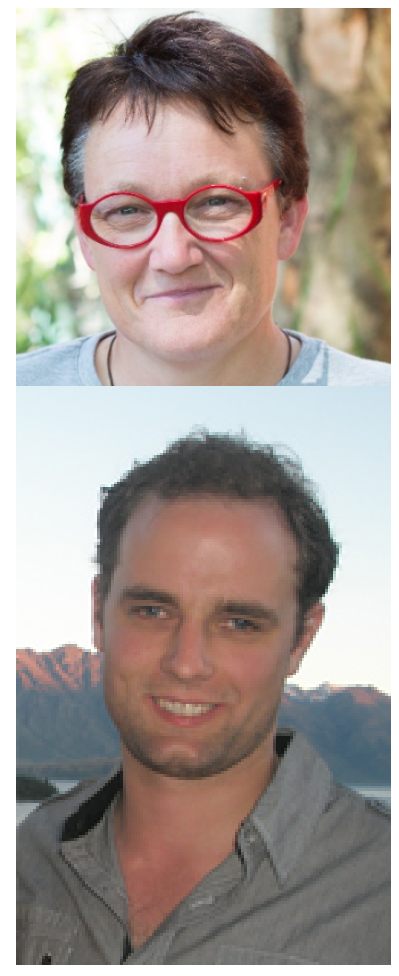

Lucy Johnston is the Dean of Graduate Studies at the University of Newcastle, Australia and formally Professor of Psychology and Dean of Postgraduate Research at the University of Canterbury, New Zealand. Her research interests include student and supervisor experiences in thesis research.

Thomas Wilson is a Senior Lecturer in Geological Sciences at the University of Canterbury, Christchurch, New Zealand. His research focuses on natural hazard and risk assessment, with special interest in volcanic eruptions, impacts of natural hazards to critical infrastructure and primary industries and community resilience to natural hazards.

Alexander MacKenzie is an Institutional Researcher within the Academic Services Group at the University of Canterbury. His interests lie in the evaluation of the student experience and student satisfaction more broadly. 